\title{
An In vitro Study to Evaluate and Compare the Dimensional Accuracy of Poly (Methyl Methacrylate) by Injection Molding and Conventional Molding Technique
}

\author{
Ambika Shrivastava Gupta ${ }^{1, \odot ~ V a i b h a v ~ A w i n a s h e ~}{ }^{2}$ \\ Arpit Jain ${ }^{4}$ \\ ${ }^{1}$ Department of Prosthodontics, Crown and Bridge and \\ Implantology, Rishiraj College of Dental Sciences and Research \\ Centre, Bhopal, Madhya Pradesh, India \\ ${ }^{2}$ Dental Faculty, Department of Dentistry in Al-Russ, Qassim \\ University, Buraydah, Saudi Arabia \\ ${ }^{3}$ Department of Prosthodontics, Rural Dental College and Hospital, \\ Loni, Maharashtra, India \\ ${ }^{4}$ Department of Oral Medicine and Radiology, College of Dental \\ Sciences and Hospital, Indore, Madhya Pradesh, India
}

Umesh Palekar ${ }^{3}$ Siddharth Gupta $\quad$ Shilpa Jain ${ }^{1}$

Dent J Adv Stud:2021;9:36-42

\begin{abstract}
Address for correspondence Ambika Shrivastava Gupta, MDS, Department of Prosthodontics, Crown and Bridge and Implantology, Rishiraj College of Dental Sciences and Research Centre, Bhopal 462016, Madhya Pradesh, India (e-mail: ambikashrivastava@gmail.com).
\end{abstract}

\author{
Abstract \\ Keywords \\ - compression molding \\ - injection molding \\ technique \\ - poly (methyl \\ methacrylate) \\ - retention
}

Introduction Poly(methyl methacrylate) is widely used as denture base material due its better physical properties, ease to fabricate, and repair. Despite being the material of choice for the denture fabrication, dentures made from poly(methyl methacrylate) may exhibit dimensional changes due to volumetric shrinkage. This further affects the retention of the denture. Various methods have been used to overcome this problem. One such method is the use of injection molding technique. So, a study was planned to evaluate the efficacy of dentures processed by injection molding technique in reducing the volumetric shrinkage.

Objective To evaluate and compare the dimensional accuracy of poly(methyl methacrylate) resin processed by conventional and injection molding technique.

Materials and Methods A total of 90 samples were made. Half of the samples (45) were fabricated by compression molding and half (45) by injection molding technique. Dimensional change was studied at three equidistant points in posterior region with the help of digitized travelling microscope. Statistical analysis was done using student's t-test.

Result Dimensional accuracy of injection molded poly(methyl methacrylate) resin was greater than that of compression molded poly(methyl methacrylate). published online December 12, 2020
DOI https://doi.org/ $10.1055 / \mathrm{s}-0040-1721551$ ISSN 2321-1482.
C2020. Bhojia Dental College and Hospital affiliated to Himachal Pradesh University.

This is an open access article published by Thieme under the terms of the Creative Commons Attribution-NonDerivative-NonCommercial-License, permitting copying and reproduction so long as the original work is given appropriate credit. Contents may not be used for commercial purposes, or adapted, remixed, transformed or built upon. (https://creativecommons.org/licenses/by-nc-nd/4.0/). Thieme Medical and Scientific Publishers Pvt. Ltd. A-12, 2nd Floor, Sector 2, Noida-201301 UP, India 


\section{Introduction}

Poly(methyl methacrylate) (PMMA) polymers were introduced as denture base materials in 1937. Since then, it has been commonly used for denture fabrication. Despite its better physical properties, ease of fabrication, and repair, dentures fabricated from PMMA exhibit dimensional changes due to volumetric shrinkage resulting in space between the palate and the definitive cast as well as heavy pressure on the lateral flange area. Such dentures have less than ideal support, retention, and stability.

Various efforts have been made in the past to control the polymerization shrinkage. One such method is the use of injection molding technique.

This study aimed at evaluating the effectiveness of injection molding technique to reduce polymerization shrinkage.

\section{Aim}

The aim of the study is to evaluate and compare the dimensional accuracy of PMMA by injection molding and conventional molding technique.

\section{Objective}

The objective is to evaluate the discrepancy at the posterior palatal seal area of the denture base by conventional molding and injection molding techniques and to compare the dimensional accuracy of PMMA by the two molding techniques.

\section{Materials and Methods}

A total of 90 samples were made, 45 were fabricated by conventional molding and 45 by injection molding technique. The dimensional change was studied at three equidistant points in the posterior palatal seal area using digitalized traveling microscope.

\section{Materials}

The materials involved are: conventional heat cure denture base resin (Lucitone 199, Dentsply), modeling wax sheet (Y-Dent), type four gypsum product (Ultrarock, Dentsply), type two gypsum product (Neelkanth), type three gypsum product (Pankaj Enterprises), cellophane sheets, soluble alginate separating medium (Cold Mol Seal-DPI), sprue wax 3-mm diameter (Dentsply), armamentarium for the preparation of samples-master dye of brass, silicone mold for master dye, mixing rubber bowl and spatula, counter aluminum dye for equal thickness of wax for each sample, vibrator, Dewax unit (dewax, Puneet Industries), hydraulic press, digitally controlled acrylizer (Dentcure, Puneet Industries), universal clamps and flask, flask for injection molding, and injection molding machine (Success, Dentsply).

For testing, digitalized traveling microscope was used.

\section{Methodology}

1. Preparation of master dyes: a brass master model was made from an ideal maxillary cast that was trimmed to half (as only the posterior palatal seal area was to be studied). On this, a counter part was fabricated in aluminum with $2 \mathrm{~mm}$ space to provide uniform thickness of the denture base.

2. Sample preparation: a silicon mold of brass dye was made. All casts were then fabricated in dye stone (Ultrarock, Dentsply), from this mold. Modeling wax (2-mm thick) was adapted on these casts using Al counterpart to achieve uniform thickness.

3. Processing of samples by compression molding technique: half of the samples were selected at random and flasking was done followed by dewaxing. The mold space was packed with heat cure acrylic resin using dough method with powder: liquid of 3:1 by volume. Curing was done in the digitally controlled acrylizer at 72 degrees for one and half hours and then increasing the temperature of the water bath to boiling for half an hour followed by bench cooling for 1 hour.

The samples were then deflasked, care was taken that the denture bases are not decasted; five samples were excluded as they separated from the cast.

4. Processing by injection molding technique: half of the samples were flasked in special injection molding flask. After dewaxing the mold was packed using injection molding system with heat cure acrylic resin using dough method with powder: liquid of 3:1 by volume. The material flowed under the pressure of $1,000 \mathrm{psi}$; it was kept under pressure for 1 minute followed by bench curing for 15 minutes. Polymerization was made standardized using same curing cycle as that was used in conventional method. Samples were then deflasked, caring that the denture bases are not casted. Five samples were excluded as they separated from the cast. The sprues from the samples were removed using carborundum disk.

5. Testing of the samples: was done at Advanced Material and Process Research Institute, Bhopal. For this, each sample was levelled and placed under the digitalized travel microscope, then zeroing of the graduated scale was done to reduce the machine error.

Three points were marked on each cast with scale, the values were respectively measured for marked points A, B, and C in whole sample size of 80 .

\section{Results and Observations}

This study includes 90 samples which were divided into two groups.

Group I: comprises of 45 samples made by injection molding technique (-Table $\mathbf{1}$ ) while in Group II: 45 samples were made by compression molding technique ( - Table 2 ).

The samples were placed under digitalized microscope to record the values at three points on each sample. 
Table 1 Group I: values for injection molding

\begin{tabular}{|c|c|c|c|}
\hline \multicolumn{4}{|l|}{ A } \\
\hline \multirow[t]{2}{*}{ S. no } & \multicolumn{3}{|c|}{ Values in micrometer } \\
\hline & Value at $\mathrm{A}$ & Value at B & Value at $C$ \\
\hline 11 & 110.9 & 208.5 & 87.9 \\
\hline 12 & 115.4 & 201.5 & 99.2 \\
\hline 13 & 132 & 285.4 & 119.0 \\
\hline 14 & 89 & 178.2 & 93.4 \\
\hline 15 & 92.7 & 110.6 & 94.3 \\
\hline 16 & 115.5 & 221.3 & 99.9 \\
\hline 17 & 119.5 & 236.1 & 109.5 \\
\hline 18 & 94.5 & 129.6 & 89.9 \\
\hline 19 & 96.5 & 110.3 & 87.8 \\
\hline 110 & 129.1 & 221.3 & 102.3 \\
\hline 111 & 278.2 & 236.1 & 149.5 \\
\hline 112 & 150.1 & 129.6 & 296.6 \\
\hline 113 & 152.4 & 115.5 & 139.6 \\
\hline 114 & 143.3 & 129.0 & 143.3 \\
\hline 115 & 159.3 & 215.6 & 148.8 \\
\hline 116 & 143.3 & 291.0 & 148.0 \\
\hline 117 & 156.2 & 244.4 & 111.1 \\
\hline 118 & 143.3 & 214.0 & 128.0 \\
\hline 119 & 109.2 & 179.1 & 88.8 \\
\hline 120 & 109.2 & 178.2 & 85.4 \\
\hline \multicolumn{4}{|l|}{ B } \\
\hline 121 & 115.2 & 156.3 & 109.2 \\
\hline 122 & 107.1 & 159.2 & 101.2 \\
\hline 123 & 88.2 & 107.2 & 100.1 \\
\hline 124 & 151.1 & 210.9 & 142.1 \\
\hline 125 & 127.0 & 178.0 & 119.1 \\
\hline 126 & 142.1 & 151.0 & 150.1 \\
\hline 127 & 121.1 & 131.0 & 129.4 \\
\hline 128 & 148 & 179.0 & 138.1 \\
\hline 129 & 142.1 & 158 & 136.0 \\
\hline 130 & 122.1 & 151.0 & 146.0 \\
\hline 131 & 110.0 & 127.0 & 120.0 \\
\hline 132 & 122.2 & 142.2 & 110.0 \\
\hline 133 & 99.8 & 152.6 & 95.4 \\
\hline 134 & 148.0 & 286.0 & 151.0 \\
\hline 135 & 131.0 & 176.0 & 142.0 \\
\hline 136 & 142.0 & 178.0 & 156.0 \\
\hline 137 & 144.0 & 179.0 & 142.0 \\
\hline 138 & 125.0 & 142.0 & 126.0 \\
\hline 139 & 110.0 & 132.0 & 99.0 \\
\hline 140 & 115.0 & 148.0 & 110.0 \\
\hline
\end{tabular}

After calculations, value at A of Group I showed a mean discrepancy of $128.8 \mu \mathrm{m}$ with a maximum discrepancy of $278.2 \mu \mathrm{m}$ and a minimum discrepancy value of $88.2 \mu \mathrm{m}$. The standard deviation in this group was found to be \pm 31.4
Table 2 Group II: values for compression molding technique

\begin{tabular}{|l|l|l|l|}
\hline \multirow{2}{*}{ S. no } & \multicolumn{3}{|c|}{ Values in micrometer } \\
\cline { 2 - 4 } & Value at A & Value at B & Value at C \\
\hline C1 & 737.9 & 237.1 & 134.6 \\
\hline C2 & 189.9 & 250.9 & 172.1 \\
\hline C3 & 725.0 & 910.0 & 729.0 \\
\hline C4 & 418.9 & 721.2 & 402.9 \\
\hline C5 & 509.1 & 720.1 & 418.9 \\
\hline C6 & 410.0 & 356.1 & 444.8 \\
\hline C7 & 712.5 & 910.5 & 725.5 \\
\hline C8 & 389.5 & 395.0 & 327.5 \\
\hline C9 & 410.0 & 721.2 & 452.0 \\
\hline C10 & 456.0 & 719.2 & 492.0 \\
\hline C11 & 359.0 & 713.0 & 420.0 \\
\hline C12 & 412.0 & 536.0 & 410.0 \\
\hline C13 & 374.7 & 307.1 & 368.8 \\
\hline C14 & 326.7 & 402.7 & 319.5 \\
\hline C15 & 388.9 & 717.7 & 415.5 \\
\hline C16 & 392.0 & 718.0 & 413.0 \\
\hline C17 & 414.0 & 718.0 & 451.0 \\
\hline C18 & 429.0 & 710.8 & 530.3 \\
\hline C19 & 493.0 & 740.0 & 531.0 \\
\hline C20 & 410.1 & 759.5 & 392.0 \\
\hline & & & \\
\hline
\end{tabular}

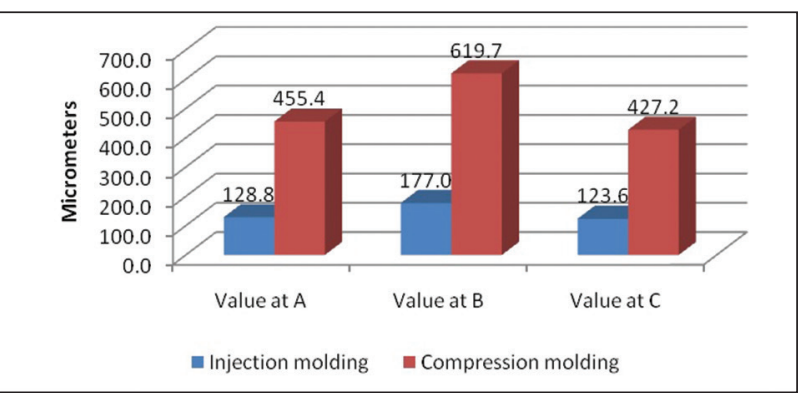

Fig. 1 Graph demonstrating mean, maximum, and minimum values at level $\mathrm{A}$ for both types of techniques.

( - Fig. 1). Value at B of Group I showed a mean discrepancy of $177.0 \mu \mathrm{m}$ with a maximum discrepancy of $291.0 \mu \mathrm{m}$ and a minimum discrepancy value of $107.2 \mu \mathrm{m}$. The standard deviation in this group was found to be \pm 49.3 ( - Fig. 2). Value at C of Group I showed a mean discrepancy of $123.6 \mu \mathrm{m}$ with a maximum discrepancy of $296.6 \mu \mathrm{m}$ and a minimum discrepancy value of $85.4 \mu \mathrm{m}$. The standard deviation in this group was found to be \pm 35.8 ( - Fig. 3; - Table 3).

Value at A of Group II showed a mean discrepancy of $455.4 \mu \mathrm{m}$ with a maximum discrepancy of $910.0 \mu \mathrm{m}$ and a minimum discrepancy value of $181.8 \mu \mathrm{m}$. The standard deviation in this group was found to be \pm 138.5 ( - Fig. 1). Value at B of Group II showed a mean discrepancy of $619.7 \mu \mathrm{m}$ with a maximum discrepancy of $910.5 \mu \mathrm{m}$ and a minimum discrepancy value of $211.8 \mu \mathrm{m}$. The standard deviation in this group was found to be \pm 191.0 ( - Fig. 2).Value at C of Group II showed a mean discrepancy of $427.2 \mu \mathrm{m}$ with a maximum 


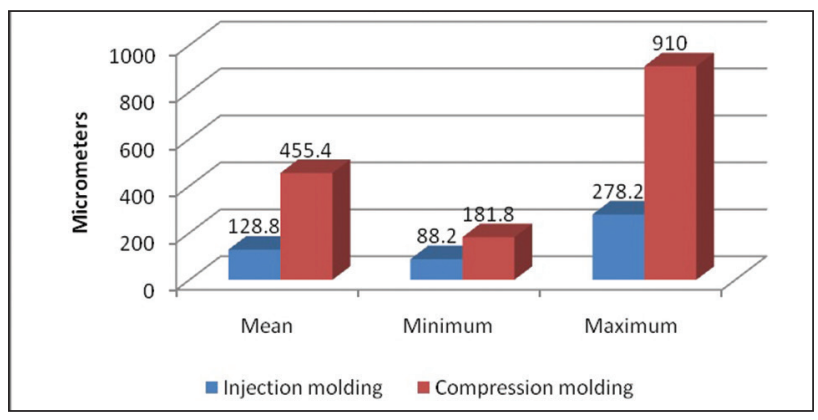

Fig. 2 Graph demonstrating mean, maximum, and minimum values at level B for both types of techniques.

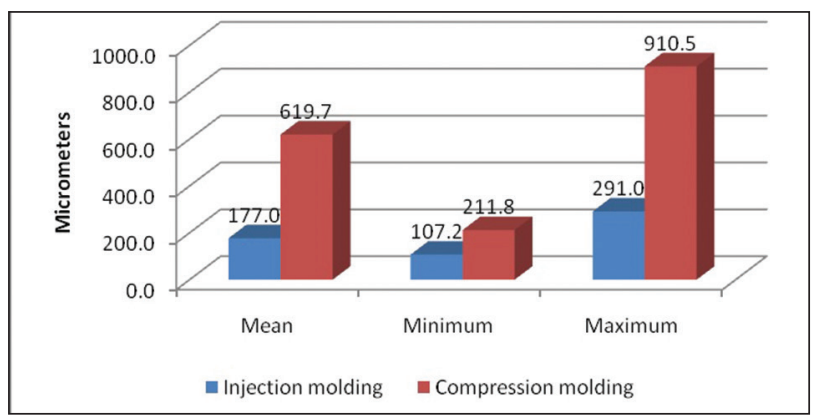

Fig. 3 Graph demonstrating mean, maximum, and minimum values at level $\mathrm{C}$ for both types of techniques. discrepancy of $920.0 \mu \mathrm{m}$ and a minimum discrepancy value of $134.6 \mu \mathrm{m}$. The standard deviation in this group was found to be \pm 149.8 ( - Fig. 3; - Table 4).

Based on the comparison of mean scores for discrepancy between value $A$ and value $B$ of injection molding by application of the Students $t$-test, a value of 5.21 was found which meant that the difference was highly significant $(p<0.05)$.

No significant difference was found on comparing mean scores for discrepancy at point $\mathrm{A}$ and $\mathrm{C}$ of injection molding.On applying Students $t$-test, a value of 0.68 was found which meant that $(p>0.05)$ there was no major difference between point $A$ and $C$. Comparison of the mean score for the discrepancy between points $B$ and $C$ of injection molding, showed a value of 5.53, which was found to be a highly significant difference.

Similarly, on comparing the values of conventional molding at A and B (4.40), values at B to values at C (5.01) are highly significant. And on comparing the scores of values at A to $C$, the difference was found to be nonsignificant $(0.87)$ (-Table 5). On comparing the values of injection molding and conventional molding at point $\mathrm{A}$, the difference was found to be highly significant. ${ }^{1}$ Similarly, on comparing the results for values of injection molding and conventional molding at $\mathrm{B}$, the difference was found to be highly significant. ${ }^{1}$ On comparison of results for values of injection molding and conventional molding at $\mathrm{C}$, by application of student " $t$ "- test, the difference was found to be highly significant.

Table 3 The statistical significance was set at 5 and $1 \%$ level of significance, i.e., $p$-value with 28 degrees of freedom

\begin{tabular}{|c|c|c|c|}
\hline $\mathrm{C} 21$ & 910.0 & 701.5 & 920.0 \\
\hline $\mathrm{C} 22$ & 412.0 & 718.0 & 420.0 \\
\hline C23 & 217.0 & 324.0 & 178.2 \\
\hline C24 & 456.0 & 720.0 & 513.0 \\
\hline $\mathrm{C} 25$ & 509.3 & 789.1 & 412.0 \\
\hline C26 & 612.0 & 715.0 & 420 \\
\hline $\mathrm{C} 27$ & 414.0 & 715.0 & 398.0 \\
\hline C28 & 388.0 & 721.0 & 398.0 \\
\hline C29 & 413.0 & 712.0 & 426.0 \\
\hline C 30 & 444.0 & 717.7 & 510.1 \\
\hline C31 & 498.6 & 594.8 & 332.9 \\
\hline C 32 & 527.9 & 440.1 & 332.9 \\
\hline C33 & 452.9 & 596.0 & 392.9 \\
\hline C34 & 444.3 & 592.9 & 275.6 \\
\hline C35 & 461.0 & 892.0 & 520.0 \\
\hline C36 & 462.9 & 565.0 & 492.0 \\
\hline C37 & 481.9 & 400.1 & 369.0 \\
\hline C 38 & 563.3 & 859.5 & 652.0 \\
\hline C39 & 406.3 & 539.0 & 391.0 \\
\hline $\mathrm{C} 40$ & 181.8 & 211.8 & 185.6 \\
\hline
\end{tabular}


Table 4 Mean, minimum, maximum and SD values of injection and compression molding techniques

\begin{tabular}{|l|l|l|l|l|l|l|l|l|}
\hline \multirow{2}{*}{ Groups } & \multicolumn{3}{|c|}{ Injection molding $(\mu \mathrm{m})$} & \multicolumn{4}{c|}{ Compression molding $(\mu \mathrm{m})$} \\
\cline { 2 - 11 } & Mean & Min. & Max. & SD & Mean & Min. & Max. & SD \\
\hline Value at A & 128.8 & 88.2 & 278.2 & 31.4 & 455.4 & 181.8 & 910.0 & 138.5 \\
\hline Value at B & 177.0 & 107.2 & 291.0 & 49.3 & 619.7 & 211.8 & 910.5 & 191.0 \\
\hline Value at C & 123.6 & 85.4 & 296.6 & 35.8 & 427.2 & 134.6 & 920.0 & 149.8 \\
\hline
\end{tabular}

Abbreviation: SD, standard deviation.

Table 5 "Student $t$-test" values

\begin{tabular}{|c|c|c|c|c|c|}
\hline Character & Mean & Mean & " $t$ " Value & Probability & Significance \\
\hline \multicolumn{6}{|l|}{ Injection molding $(\mu m)$} \\
\hline Value $A$ and Value $B$ & 128.8 & 177.0 & 5.21 & 0.000 & Highly significant \\
\hline Value $A$ and Value $C$ & 128.8 & 123.6 & 0.68 & 0.497 & Non-significant \\
\hline Value $B$ and Value $C$ & 177.0 & 123.6 & 5.53 & 0.000 & Highly significant \\
\hline \multicolumn{6}{|l|}{ Compression molding $(\mu \mathrm{m})$} \\
\hline Value $A$ and Value $B$ & 455.4 & 619.7 & 4.40 & 0.000 & Highly significant \\
\hline Value $\mathrm{A}$ and Value $\mathrm{C}$ & 455.4 & 427.2 & 0.87 & 0.386 & Nonsignificant \\
\hline Value $B$ and Value $C$ & 619.7 & 427.2 & 5.01 & 0.000 & Highly significant \\
\hline \multicolumn{6}{|c|}{ Injection and compression molding $(\mu \mathrm{m})$} \\
\hline $\begin{array}{l}\text { Value A (at injection molding and } \\
\text { compression molding) }\end{array}$ & 128.8 & 455.4 & 14.54 & 0.000 & Highly significant \\
\hline $\begin{array}{l}\text { Value B (at injection molding and } \\
\text { compression molding) }\end{array}$ & 177.0 & 619.7 & 14.19 & 0.000 & Highly significant \\
\hline $\begin{array}{l}\text { Value } C \text { (at injection molding and } \\
\text { compression molding) }\end{array}$ & 123.6 & 427.2 & 12.46 & 0.000 & Highly significant \\
\hline
\end{tabular}

\section{Discussion}

Various factors affect the success of complete denture treatment like retention, stability, support, esthetics, and preservation of remaining structures. Among these, retention of denture is of utmost importance to the patient. It not only enhances the denture stability but also helps to solve various psychological problems encountered by the patient during the learning or the re-educating period. Retention is related to the adaptation (fit) of its base to the bearing areas. This, however, depends on many factors which include the method and the material used for its construction. ${ }^{2}$

Various materials like bone, ivory, vulcanite, aluminum, have been tested in the past for making of the dentures. But the transition to PMMA since 1938 has been very rapid. Due to its color stability, translucency, ease of fabrication, and repair it is most exclusively used today. ${ }^{3}$ Although dentures constructed of PMMA have many desirable qualities than materials previously used, ${ }^{4}$ problem exists with denture base adaptation. Volumetric shrinkage of about $6 \%$ occurs during polymerization process which is caused by the differences in the densities of the monomer and the polymer, ${ }^{5}$ resulting in the lifting of denture base from posterior palate after polymerization.

A good adaptation of the denture base is important for a favorable thin saliva film, the adaptation of posterior border is particularly important because it completes the peripheral seal formed by the entire border of the denture. ${ }^{6}$
Shrinkage of the denture base material is observed as pulling away or lifting off of the base from the cast in the posterior mid palatal area. ${ }^{7}$ The material is pulled from area of lesser bulk to the ridges having greater bulk. The posterior mid palatal area undergoes the greatest distortion. ${ }^{8}$ Various procedures and methods have been advocated to compensate for these dimensional changes that occur during processing.

Compression molded methyl methacrylate has been the standard denture base material for more than 60 years. Undesirable dimensional changes occur during processing by this method. ${ }^{9}$ To overcome some of these dimensional changes, Pryor introduced injection molding system. ${ }^{10}$ This system compensates the shrinking of acrylic resin by the continuous injection of resin under pressure during the polymerization process. ${ }^{10,11}$

This study was therefore conducted to evaluate and compare the dimensional accuracy of injection molding and conventional processing of PMMA resin. It has been stated previously that greatest changes were found in cross arch dimension. ${ }^{5}$ Thus, considering this fact, the posterior palatal seal area was taken into account for the study which is in accordance with Sykora and Sutow, ${ }^{12}$ Laughlin and Eick. ${ }^{13}$

An ideal maxillary cast was selected for fabrication of the denture base, but since posterior palatal seal area was only to be studied, the anterior half of the cast was trimmed off. All the casts for samples were fabricated with the help of silicone mold of brass master dye. 
To fabricate an equal thickness of denture base, an aluminum counterpart was fabricated with uniform space of $2 \mathrm{~mm}$, with the help of this, wax was adapted for processing of all the denture bases.

Forty-five samples were fabricated by conventional compression molding technique and the remaining samples by injection molding technique. After processing, but before decasting, each cast was mounted under digitalized traveling microscope to measure the adaptation discrepancy between the inner surface of the denture base and the cast at three points marked on posterior palatal border of the denture base.

Various other methods have been documented for recording this discrepancy, such as travelling microscope, ${ }^{14,15}$ toolmaker's microscope, ${ }^{16-18}$ digital vernier caliper, ${ }^{14,19,20}$ optical comparator,,21-23 Gaertner microscope, ${ }^{2}$ antographic measuring device, ${ }^{24,25}$ and thickness gauge. ${ }^{26}$ However, digital traveling microscope was used as it reduces the manual error.

On comparing Group I and Group II, it was found that the variation in Group I was comparatively lesser than Group II. These results support that injection molding technique has less inherent processing shrinkage probably due to continuous application of pressure to the injection molding system (Group I) and the subsequent layering processing of the base material. These findings are in accordance with Anderson et al, ${ }^{1}$ Strohaver, ${ }^{23}$ Hugget et al. ${ }^{27}$

Similar observation regarding dimensional accuracy of injection molding was described by authors such as Salim et al. ${ }^{28}$ Nogueira et al ${ }^{29}$ concluded that injection molding was a more accurate method of processing dentures. They also found no appreciable differences in laboratory working time between the injection and compression molding techniques. Garfunkel $^{30}$ found no significant difference between the two processing techniques.

On comparison of Group I value at point A to values at B, and value at point $B$ to value at $C$, there was a variation and the discrepancy was found to be highly significant; these result are similar to observations given by Sykora and Sutow. ${ }^{12}$

Similarly, the intradifferences between Group II were also highly significant between value $A$ and value $B$, value $B$ and value $\mathrm{C}$.

Thus, the hypothesis $\left(\mathrm{H}_{1}\right)$ that there is a significant decrease in the discrepancy of injection molded samples (Group I) compared with compression molded sample (Group II). This study therefore suggests that injection molding should be the choice for processing of denture bases of PMMA, as it compensates for the inherent property of polymerization shrinkage and reduces discrepancy at posterior palatal seal area.

\section{Summary and Conclusion}

Despite being one of the oldest dental treatments, complete denture fabrication is still fraught with both extrinsic and intrinsic potential error. The valuable properties of PMMA made this resin as the choice for denture base. Indeed, by 1946 , it was estimated that $95 \%$ of all dentures are constructed of methyl methacrylate polymers. Though being the material of choice for denture base fabrication, the inherent property of polymerization shrinkage produces undesirable changes in the dimensional accuracy of the dentures.

With the advent of technology, many attempts have been made to improve the accuracy of denture by special methods of processing, such as injection molding technique.

This study, therefore, evaluated and compared the dimensional accuracy of injection molding and conventional molding technique of PMMA resin. In this study, 90 denture base samples, 45 each made by injection molding (Group I) and conventional molding (Group II), respectively were compared at three points on posterior palatal seal region for discrepancy.

All the samples were tested under digitalized traveling microscope and the discrepancy was recorded for each sample at the three points. Statistical analysis was further performed after which the following conclusions were drawn:

1. The dimensional accuracy of injection molded PMMA resin was found to be better than that for compression molded PMMA resin.

2. The dimensional discrepancy at posterior palatal seal region of injection-molded denture bases was found to be significantly less than the discrepancy found in that of compression-molded denture bases.

3. From this study we concluded that injection molding technique produced better adaptation of the denture base.

\section{Conflict of Interest}

None declared.

\section{References}

1 Parvizi A, Lindquist T, Schneider R, Williamson D, Boyer D, Dawson DV. Comparison of the dimensional accuracy of injection-molded denture base materials to that of conventional pressure-pack acrylic resin. J Prosthodont 2004;13(2):83-89

2 Zissis A, Huggett R, Harrison A. Measurement methods used for the determination of dimensional accuracy and stability of denture base materials. J Dent 1991;19(4):199-206

3 Murray MD, Darvell BW. The evolution of the complete denture base. Theories of complete denture retention-a review. Part 1. Aust Dent J 1993;38(3):216-219

4 Rueggeberg FA. From vulcanite to vinyl, a history of resins in restorative dentistry. J Prosthet Dent 2002;87(4):364-379

5 Powers JM, Sakaguchi RL, eds. Craig's Restorative Dental Material. 12th ed. Mosby; 2006:513-551

6 Woelfel JB, Paffenbarger GC. Dimensional changes occurring in artificial dentures. Int Dent J 1959;9(4):451-460

7 Latta GH Jr, Bowles WF II, Conkin JE. Three-dimensional stability of new denture base resin systems. J Prosthet Dent 1990;63(6):654-661

8 McCartney JW. Flange adaptation discrepancy, palatal base distortion, and induced malocclusion caused by processing acrylic resin maxillary complete dentures. J Prosthet Dent 1984;52(4):545-553

9 Mahler DB. Inarticulation of complete dentures processed by the compression molding technique. J Prosthet Dent 1951;1(5):551-559

10 Pryor WJ. Injection molding of plastics for dentures. J Am Dent Assoc 1942;29(1):1400-1408 
11 Anderson GC, Schulte JK, Arnold TG. Dimensional stability of injection and conventional processing of denture base acrylic resin. J Prosthet Dent 1988;60(3):394-398

12 Sykora O, Sutow EJ. Posterior palatal seal adaptation: influence of processing technique, palate shape and immersion. J Oral Rehabil 1993;20(1):19-31

13 Laughlin GA, Eick JD, Glaros AG, Young L, Moore DJ. A comparison of palatal adaptation in acrylic resin denture bases using conventional and anchored polymerization techniques. J Prosthodont 2001;10(4):204-211

14 Grant AA, Atkinson HF. Comparison between dimensional accuracy of dentures produced with pour-type resin and with heat-processed materials. J Prosthet Dent 1971;26(3): 296-301

15 de Gee AJ, ten Harkel EC, Davidson CL. Measuring procedure for the determination of the three-dimensional shape of dentures. J Prosthet Dent 1979;42(2):149-153

16 Mowery WE, Burns CL, Dickson G, Sweeney WT. Dimensional stability of denture base resins. J Am Dent Assoc 1958; 57(3):345-353

17 Woelfel JB, Paffenbarger GC, Sweeney WT. Dimensional changes occurring in dentures during processing. J Am Dent Assoc 1960;61:413-430

18 Hardy F. Comparison of fluid resin and compression molding methods in processing dimensional changes. J Prosthet Dent 1978;39(4):375-377

19 Mirza F. Dimensional stability of acrylic resin dentures. J Prosthet Dent 1961;11:848-857

20 Johnson DL, Duncanson MG Jr. The plastic post palatal denture seal. Quintessence Int 1987;18(7):457-462
21 Barsoum WM, Eder J, Asgar K. Evaluating the accuracy of fit of aluminum-cast denture bases and acrylic resin bases with a surface meter. J Am Dent Assoc 1968;76(1):82-88

22 Becker CM, Smith DE, Nicholls JI. The comparison of denture-base processing techniques. Part II. Dimensional changes due to processing. J Prosthet Dent 1977;37(4): 450-459

23 Strohaver RA. Comparison of changes in vertical dimension between compression and injection molded complete dentures. J Prosthet Dent 1989;62(6):716-718

24 Antonopoulos AN. Dimensional and occlusal changes in fluid resin dentures. J Prosthet Dent 1978;39(6):605-615

25 Peyton FA, Anthony DH. Evaluation of dentures processed by different techniques. J Prosthet Dent 1963;13(2):269-281

26 Kraut RA. A comparison of denture base accuracy. J Am Dent Assoc 1971;83(2):352-357

27 Huggett R, Zissis A, Harrison A, Dennis A. Dimensional accuracy and stability of acrylic resin denture bases. J Prosthet Dent 1992;68(4):634-640

28 Salim S, Sadamori S, Hamada T. The dimensional accuracy of rectangular acrylic resin specimens cured by three denture base processing methods. J Prosthet Dent 1992;67(6):879-881

29 Nogueira SS, Ogle RE, Davis EL. Comparison of accuracy between compression- and injection-molded complete dentures. J Prosthet Dent 1999;82(3):291-300

30 Garfunkel E. Evaluation of dimensional changes in complete dentures processed by injection-pressing and the pack-and-press technique.J Prosthet Dent 1983;50(6):757-761 